\title{
Introduction to Energy Systems Modelling
}

\author{
Andrea Herbst, Felipe Toro, Felix Reitze, and Eberhard Jochem
}

JEL-Classification: C63, L61

Keywords: energy modelling, bottom-up, top-down, hybrid energy system modelling, Switzerland

\section{Introduction}

Controversial discussions in energy science and energy policy communities about the perspectives, feasibility and impacts of future energy demand and supply can often be traced back to the different types of energy models used and their results (e.g. Krause 1996). Detailed techno-economic (or process-oriented) models can simulate the market penetration and related cost changes of a new energy technology or policy with a certain degree of technical detail (which is why they are called "bottom-up" models). However, they cannot project the corresponding economic, structural, or employment net impacts or net cost for society. The results of these models are often cited by environmentally-concerned scientists, NGOs and politicians to elucidate the feasibility of major changes to the energy system, particularly in the context of urgent and extensive change of the mainly fossil fuelled energy systems in almost all countries.

On the other hand, macroeconomic models (also called top-down models) can simulate sector-specific future energy demand and supply including the impacts on economic growth, employment or foreign trade. However, they rely very much on energy price changes and financial policies and are not well suited to describe the development of specific technologies or sectoral policies and related changes in energy demand, related emissions, and investments at a sufficiently detailed level. They may also reflect rather constant trends in structural changes of the economy and, to an unsatisfactory extent, saturation processes and innovations. The results of these models are often cited by representatives of trade associations, large energy-intensive or energy supply companies, and conservative politicians.

The present discussions in Switzerland or Germany are good examples, where anti-nuclear NGOs refer to the feasibility of a non-nuclear, low carbon Swiss energy system and the German government has re-decided for a phase out in the beginning 2020s by citing the results of bottom-up models. On the other hand, economiesuisse (the Swiss Business Federation) and other Swiss trade associations 
as well as the BDI (the German Trade Association of Industry) point to the high and unacceptable economic risks of such an energy system by referring to macroeconomic results of top-down models such as losses in economic growth, employment and competitiveness.

Each of the two types of models has its specific advantages and limitations. This paper addresses in greater detail some of the challenges that have to be met when combining the two types of models via electronically-based modules (a so called 'hard' link). There is no doubt that combining the advantages of both types of energy models into a hybrid model will more adequately describe and project the changes of the energy system, which may improve the quality of discussions on future energy perspectives by being able to differentiate among technologies and sectors, and to analyse the macroeconomic implications of large policy portfolios and major changes of the energy system in a consistent and transparent manner (BÖHRINGER, 1998).

\section{Overview of Energy Modelling Approaches - State-of-the-Art}

Energy models are used to project the future energy demand and supply of a country or a region. They are mostly used in an exploratory manner assuming certain developments of boundary conditions such as the development of economic activities, demographic development, or energy prices on world markets. They are also used to simulate policy and technology choices that may influence future energy demand and supply, and hence investments in energy systems, including energy efficiency policies.

However, policy and technology choices induce a dilemma in the choice of energy model (BöHringer, 1998). Detailed techno-economic (or process-oriented) models were first developed in the early 1970s, particularly after the first oil crisis in 1973, when analysts started to examine the options of oil use and the more efficient use of final energies. Modern macroeconomic energy models have their origin in the late 1950s, when energy supply companies and energy administrations had to make decisions about the future energy supply to meet the rising energy demand of the rapidly developing OECD countries.

Every modelling approach abstracts to a certain degree from reality using stylized facts, statistical average figures, past trends as well as other assumptions. Consequently, energy models represent a more or less simplified picture of the real energy system and the real economy; at best they provide a good approximation of today's reality. Nevertheless, it would be impossible to answer very specific questions on energy technologies or economic implications without making 
some cut backs and approximations, with an uncertain reliability on quantitative figures used by those models. A large diversity of modelling approaches has been developed over time depending on their target group (policy makers, scientific and research communities, large energy supply companies), intended use (data analysis, ex post evaluation, forecasting, simulation, optimization, estimation of parameters, etc.), regional coverage (regional, national, multinational), conceptual framework (top-down: underlying economic theory, bottom-up: technological focus/explicitness) and the information available (data on final energy, useful energy, energy demand by branches in the service, transport, or industrial sector).

Obviously, both types of energy models, top-down and bottom-up, have specific advantages and limitations, of which modellers, users of the results, and policymakers are, however, often not sufficiently aware. Bottom-up models are generally constructed and used by engineers, natural scientists, and energy supply companies, whereas top-down models tend to be developed and used by economists and public administrations. The understanding of the two approaches has increased substantially over the last decade (BöHRINGER and RUTHERFORD, 2006, 2008; HourCade et al., 2006); There have been first few attempts to combine both approaches in one hybrid energy model system, probably so late during the past decade due to the lack of interdisciplinary research teams of necessary larger funds for their operation (HourCADE et al., 2006; Jochem et al., 2007; Schade et al., 2009; Catenazzi, 2009).

Recent or current projections and studies of energy demand and supply using energy models (E3Mlab, 2007; BFE, 2007; WWF, 2009; IEA, 2010; Prognos, 2011) are not just made for routine decisions by decision makers in administrations or large energy companies; they also increasingly serve as a scientifically derived information basis for societal debate among governments, energy companies, trade associations, and NGOs. The recent discussions about greenhouse gas emission targets (and target sharing) in EU Member countries, phasing out nuclear energy after Fukushima in some European countries and Japan, and the speed of introducing renewable energies and realising energy efficiency potentials have been increasingly influenced by the results taken from various energy demand and supply models developed during the last two decades.

The following sections describe selected top-down and bottom-up models, their main advantages and limitations as well as examples of their implementation. These descriptions are also intended to shed some light on the existing preferences of the various stakeholders in the energy field and in the economy. 


\subsection{Top-Down Energy Models}

Top-down energy models try to depict the economy as a whole on a national or regional level and to assess the aggregated effects of energy and/or climate change policies in monetary units. In contrast to bottom-up modelling, these equationbased models take an aggregated view of the energy sectors and the economy when simulating economic development, related energy demand and energy supply, and employment. Driven by economic growth, inter-industrial structural change, demographic development, and price trends (rather than energy-related technological progress, innovations, or intra-industrial structural change), macroeconomic models try to equilibrate markets by maximizing consumer welfare using various production factors (labour, capital, etc.) and applying feedback loops between welfare, employment, and economic growth. Currently, macroeconomic energy models are often being used to evaluate the economic costs and environmental effects of general energy or climate policy instruments, such as energy or $\mathrm{CO}_{2}$ taxes or surcharges, emission trading schemes (ETS), feed-in tariffs of renewable energies, etc. (BATAILle, 2005).

In the past, conventional top-down energy models considered technology developments mainly in the context of price-based policies (taxes, surcharges, or investment subsidies) and regulatory policies (technical standards, bans, and technological targets). In current top-down modelling approaches, efforts are made to extend the energy demand forecasting framework of the existing models to include technological and economic feedbacks (LÖsCHEL, 2002; BöHRINGER and Löschel, 2006) as well as non-price policies (technical standards, norms, etc.; Worell et al., 2004). A good example in this context is the global optimization model MERGE which combines a top-down approach to model economy and energy demand with a bottom-up approach to depict the energy sector (MANNE and Richels, 2004).The following subsections present four different types of top-down models: input-output models, econometric models, computable general equilibrium models and system dynamics.

\subsubsection{Input-Output Models}

The traditional Input-Output Analysis is based on Francois Quesnays Tableau économique (1758) and Leon Walras and Wassily Leontiefs InputOutput Economics (1966). Used for a structural description of the regarded economy, it describes the total flow of goods and services of a country subdivided into different sectors and users in terms of value added and specific input/output coefficients. Input-output tables are more suitable for short-term evaluation of energy policies rather than long-term ones as they can only give a 
current picture of the underlying economic structure based on historical data (Catenazzi, 2009).

For Switzerland, Nathani et al. (2006) developed a two-step approach for generating a balanced input-output table based on the European Union inputoutput table structure (Eurostat, 2008). By using country comparisons (particularly with Austria and Germany) and the cross-entropy method, Nathani et al. (2006) tackled data limitations concerning the Swiss economy and generated a good overall picture of its sectoral interdependencies. However, there is still room for general model improvements relating to deficient data as well as on a sectoral level for specific industries (e.g. paper industry) where major uncertainties have been observed.

Various studies additionally introduced energy issues into the economic framework of input-output analysis. For example, NATHANI (2006) showed for the special case of Germany that the application of input-output tables could be useful to examine the interrelationships between material use and the energy demand of an economy with regard to material efficiency improvements using sectorspecific energy intensities. Another example is the hybrid energy input-output table of the German Federal Statistical Office within the Environmental-Economic Accounting for Germany (MAYER, 2007) or the input-output analysis of the United Nations (United Nations, 1999).

\subsubsection{Econometric Models}

Econometric analysis has been defined as a combination of economic theory, mathematical tools and statistical methods (Tinter, 1953). Early (basic) econometrics was aimed at testing economic theory (estimation of economic relationships) using empirical evidence. However, over the course of time the requirements made of econometrics increased from pure hypothesis testing to the development of complex econometric models. Additionally, most of the econometric energy models are open-ended, growth-driven macro econometric models using/analysing time series data on a higher level of aggregation, e.g. output, etc. with no assumption of equilibrium, while cross section and panel data tend to be applied more in micro econometrics (Wooldridge, 2002; Greene, 2003).

One major disadvantage of econometric models is their heavy reliance on data. To be able to generate credible results, econometric models need huge amounts of data for fairly long time periods. There may be a general problem of data availability for the modellers in the case of small macro econometric models, which will probably be exacerbated in the case of multi-country analyses where data for some countries might not be available at all or not comparable due to national 
accounting or census differences. In this context the credibility and adequacy of data represent additional uncertainties for model quality (e.g. rough guesses, methods of estimation, etc.).

E3ME (CAMECON, 2011) is an annual macro econometric model simulating GDP at the level of 41 branches for all EU Member States, with implications for employment, gross value added, prices and several other economic, energy and environmental variables. It has been developed by Cambridge Econometrics with the aim to address the long-term effects of energy-economy-environment (E3) policies at the European level, especially those concerning investment, $\mathrm{R} \& \mathrm{D}$, and environmental taxation and regulation (Jochem et al., 2007).

\subsubsection{Computable General Equilibrium Models}

Historically, Computable General Equilibrium (CGE) models have their origins in the general equilibrium theory developed by LÉON WALRAs ${ }^{1}$ in the 1870s, Vilfredo Pareto ${ }^{2}$ in 1906 and Kenneth Arrow and Gerard Debreu ${ }^{3}$ in the 1950s. However, current CGE models may use different approaches to analyse policy implications for economies (e.g. Keynesian models). Generally, these kinds of model assume that all markets are in perfect equilibrium to start with (no excess demand or supply, no obstacles to profitable potentials of energy efficiency). CGE models use Social Accounting Matrices (SAM) to represent their benchmark data in equilibrium. After policy intervention (e.g. introduction of special taxes or subsidies, etc.), the equilibrium is preserved by price adjustments which cannot be influenced by the involved agents (e.g. households, firms, and government) as they act as price takers and try to maximize their welfare or profits under certain constraints and quantity adjustments. In practice, researchers and international institutions commonly use CGE models for long term simulations like, e.g. the GEM-E3 model of the European Commission, the GTAP model consortium, or the World Bank models.

Through its equilibrium approach, CGE models rule out energy efficiency gaps, adjustment delays and consequently neglect the importance of market failures and obstacles. Additionally, like the majority of pure macroeconomic models, CGE models do not take technological details into account which might be important for the assessment of certain policy measures (see HourCade et al., 2006).

1 Éléments d'économie politique pure, ou théorie de la richesse sociale (1874)

2 Manuale d'economia polititica (1906)

3 The Existence of an Equilibrium for a Competitive Economy (1954) 
The recursive dynamic GEM-E3 CGE model simulates interactions between the economy, the energy system and the environment as well as the macroeconomic effects of environmental policies (taxes, standards, tradable permits, etc.) for 15 (or 27) European countries and considering four economic agents (households, firms, governments and foreign trade) (CApros et al., 1996a, 1996b). On the supply side, the market consists of five production sectors, agriculture, energy, manufactured goods and services (divided into 18 branches) with labour and capital as input factors. Technological progress enters the GEM-E3 model through its production function, either modelled endogenously or taken from outside the model (expert estimates, etc.). On the demand side, 13 categories of durable and non-durable consumption goods enter the markets. In addition, foreign trade (imports and exports) enters the model under the "Armington" assumption of imperfect substitutes. Extensions were made to the basic GEM-E3 model to cover macroeconomic effects under imperfect competition as well as geographical expansion (Eastern European countries, Switzerland) (CES, 2008).

GEM-E3 Switzerland was developed by BAHN and FreI (2000) and was later merged into the European GEM-E3 model for the European Union. Their main aim was to compile a reliable Swiss database for GEM-E3 as well as to evaluate different $\mathrm{CO}_{2}$-emission reduction strategies for Switzerland. Another CGE model of that family is the GEMINI-E3 model (developed by the French Ministry of Equipment and the French Atomic Energy Agency). This model family consists of several CGE models, one of them specifically tailored to Switzerland computing the costs of the Kyoto Protocol for Switzerland with and without international emissions trading. GEMINI-E3 models very detailed indirect taxation and social contributions rates and puts a special focus on the measurement and analysis of welfare cost of policies (BERNARD and VieLLE, 2008).

\subsubsection{System Dynamics}

The modelling concept of System Dynamics (SD) was developed by ForRester $(1958,1962,1971,1980)$ in the 1950s at the Massachusetts Institute of Technology (MIT) and used to analyse the long-term behaviour of social systems like large industrial companies or entire cities. The aim here is to explain the behaviour of an interacting social system as a result of the assumed interdependencies considering dynamic changes over time (differential equations and analysis) among the various components that constitute the defined system. The model developer defines flows, stocks, and central components of the defined system, whose interconnections are established by feedback control systems or feedback 
loops represented by non-linear differential equations. Another element which is integrated in system dynamics theory and methodology concerns the decision theory of (designed) modelled complex social systems. In addition, information technologies for computational analysis and a graphical interface to represent feedback loops are typical features of system dynamics models and form the basis for discussions of the analysed social systems by interdisciplinary teams (KraIL and Schade, 2010).

The development over time of the defined systems is described using differential analysis with mathematical formulations. Forrester and his associates developed software tools in order to use difference equations to calculate the dynamic equations of the feedback system and its development over time incorporating expert judgements. These programmes provide the capabilities to follow an experimental modelling approach if no analytical or data-based solutions are available.

Examples of system dynamics approaches applied to analyse long-term developments in the energy sector include the TIME-model investigating long-term structural developments within the worldwide energy system (DE VRIES et al., 1999), the POLES model replicating the whole energy system (Russ and CRIQUI, 2007) and the ASTRA model in the transport sector (SCHAdE, 2004) that was extended to macroeconomic structures (KraIL and Schade, 2010). The macroeconomic module integrates neoclassical production functions with Keynesian consumption and investment behaviour and with elements of endogenous growth theory to incorporate technological progress.

Drawbacks of system dynamics relate to the validation and calibration of the assumed feedback loops, in particular with reference to the modelling of longterm developments in the energy systems (Fichtner et al., 2003) and also the inability to make detailed analyses and projections of sectoral technologies.

\subsection{Bottom-Up Energy Models}

The main characteristic of a conventional bottom-up energy model is its relatively high degree of technological detail (compared to top-down energy models) used to assess future energy demand and supply. In contrast to top-down models, bottom-up models use a business economics approach for the economic evaluation of the technologies simulated. They usually cannot consider macroeconomic impacts of energy or climate policies or related investments. They do not consider transaction costs which are implicitly covered by top-down models. Their technological detail and transparency considering technological progress and the diffusion of new energy technologies make bottom-up energy models unsuitable for very long-term energy demand and supply projections in technology areas 
with re-investment cycles of less than 20 years (e.g. future generations of a new technology may be quite different from its present type).

Regarding the mathematical form, bottom-up energy models have been developed in the form of simulation or optimisation models, and more recently of multi agent models (see below). Bottom-up modellers try to identify the best technologies by assessing policies, their effects, investment, costs, and benefits, by calculating external benefits (e.g. environmental, etc.) of energy efficiency measures, by identifying synergy-effects between sectors, and sectoral costs and surpluses. However, most bottom-up models limit their investment and cost calculations to the conversion sector and cross cutting technologies in the final energy sectors if it comes to energy efficiency options. This fact is often overlooked and leads to questionable conclusions in cases of scenario comparisons and model comparisons.

\subsubsection{Partial Equilibrium Models}

Partial equilibrium models do not differ greatly from the already mentioned CGE models as the framework and mechanisms are very similar. However, partial equilibrium models assess only one sector or a certain subset of sectors. Partial equilibrium energy models focus on energy demand and supply. By neglecting certain interrelations and effects on the broader economy, they can include many more technological details than conventional CGE models. Important partial equilibrium models include, amongst others: the POLES (Prospective Outlook on Long-term Energy System) model from Enerdata, the WEM (World Energy Model) of the International Energy Agency, and the PRIMES Energy System Model of the European Commission. It should be pointed out, however, that the cited models are not pure partial equilibrium models because they already attempt to bridge macroeconomic and process-oriented approaches, e.g. by combining explicit technology choices with microeconomic relationships.

The POLES model analyses the international energy markets for seven world regions, eleven sub-regions and 32 countries, considers about 40 technologies of power and hydrogen production and the final energy sectors in some detail. It is based on a recursive simulation process in which the energy demand and supply for each national or regional module reacts to international price changes in the previous period. Each module considers not only price effects but also technological and economic constraints and trends (ENERDATA, 2011).

The WEM is a large-scale mathematical model that generates medium- to long-term sectoral and regional projections of energy demand, power generation, etc. on a global and regional level. The model consists of several demand modules 
(final energy demand of industry, transport, the residential sector and services), a refinery module, a power generation module, three fossil fuel supply modules (gas, oil, and coal) as well as a module which calculates, amongst others, the $\mathrm{CO}_{2}$ content factors for coal, oil and gas for different sectors and regions. Additionally the model estimates supply-side investments as well as the net change to demand-side investments based on its energy supply and demand projections for three scenarios (IEA, 2011).

PRIMES is used to analyse, for example, the impacts of carbon emission trading and of renewable and energy efficiency policies on energy markets by simulating a market equilibrium for energy demand and supply up to 2030 within each of the EU Member States including endogenous energy price formation. The model consists of 11 sub-models, including several demand- and supplyside modules and, in contrast to other energy models, utilises more recently agent-based objective functions which, however, are not publicly documented (E3MLAB, 2007).

\subsubsection{Optimisation Models}

Optimisation models try to define the optimal set of technology choices to achieve a specific target at minimised costs under certain constraints leaving prices and quantity demanded fixed in its equilibrium. The MARKAL model analyses energy demand and supply on a country level using a bottom-up, dynamic modelling approach. Like the above mentioned partial equilibrium models, MARKAL already combines a detailed bottom-up model with a simplified macroeconomic approach. It was developed by the International Energy Agency and designed to support policymakers by providing them with detailed information about energy technologies on the demand and (mostly) supply sides. According to ETSAP (2011), MARKAL aims at identifying a least-cost energy system with cost-effective responses to restraints on emissions. Additionally, price-based policies (taxes, etc.) as well as new technologies and trends in technological change are evaluated and the degree of regional cooperation is estimated. Today, there are several versions of the original MARKAL model including a small macroeconomic model, a microeconomic model, and various added features such as endogenous energy demand projection, responsiveness to price changes, trade of emission permits, uncertainties regarding endogenous technology learning (Seebregts et al., 2002; Loulou et al., 2004).

The TIMES model (The Integrated MARKAL-EFOM System) is one of these MARKAL family models and based on the same modelling approach as the conventional MARKAL model used for overall- and single-sector analysis of 
the energy market. In comparison with the usual MARKAL model, the TIMES model provides some special features: flexible time periods, data decoupling, process generality, flexible processes, commodity related variables, climate equations, etc. (ETSAP, 2005) Euro MM (European Multi-regional MARKAL), another offspring of the MARKAL model family, is an multi-country energy system optimisation model which evaluates policy and climate change impacts on the energy conversion sector by calculating the least-cost solutions for the energy system (SCHADE et al., 2009).

Another energy supply optimization model frequently cited in literature is MESSAGE (Model for Energy Supply Strategy Alternatives and their General Environmental Impact) developed by the Austrian International Institute for Applied Systems Analysis (IIASA) hosting 11 regions and computing the evolution of the energy sector up to the year 2100 (Messner and Strubegger, 1995).

The DIME (Dispatch and Investment Model for Electricity markets in Europe) model is designed as a linear optimisation model for medium- and long-term forecasting of the European (13 Central and Western European countries including Switzerland) electricity generation market covering 11 technologies for electricity generation. Based on the assumptions of a competitive power generation market it minimises costs and is applied to simulate allocation as well as investment decisions regarding the supply side of the electricity sector (EWI, 2011).

The use of optimisation models is limited to discrete energy conversion technologies and typified energy uses (such as cars, different types of insulated houses) as the information on investment and operating cost are needed for the optimisation. This central requirement of optimisation models limits their application to certain technological areas and final energy sectors. It is impossible, for instance, to simulate the energy demand of the service and industrial sector due to their technological variety where cost information cannot be made available. In addition, optimisation models neglect the fact that severe market imperfections and obstacles in many final energy sectors and also the conversion sector (e.g. co-generation) are not simulated leading to unrealistically low projections of energy demand.

\subsubsection{Simulation Models}

Simulation models aim to replicate consecutive rules that describe the associations and interrelationships among various system elements, i.e., simulation models attempt to provide a descriptive, quantitative illustration of energy demand and conversion based on exogenously determined drivers and technical data with the objective to model observed and expected decision-making that does not follow a 
cost minimising pattern. Replicating in a simplified manner final user behaviour by modelling their technological choices is based on the variation of pre-defined drivers (e.g. income, population, employees, living area, mileage, government policies, energy prices, etc.). These drivers are correlated with the general economic and demographic development (i.e. scenarios) as well as other boundary conditions (e.g. energy and climate change policies).

Traditionally, the operation and planning of the electricity sector have been simulated using cost minimisation models (see Section 2.2.2.). However, these models are not well suited to the more recent framework which developed due to the electricity sector being restructured and liberalised in most countries (Linares et al., 2008) and therefore several scientists have developed models that also consider imperfect competition as reviewed in Ventosa et al. (2005). Simulation models are flexible and allow aspects such as strategic behaviour or the absence of complete information to be integrated which help to mirror market imperfections and failures. Well-known examples of this category of simulation model include system dynamics (SD) and agent-based simulation models (see Section 2.2.4). Specific examples include the Residential End-Use Energy Planning System (REEPS); World Energy Model (WEM); Mesures d'Utilisation Rationnelle de l'Energie (MURE); and the National Energy Modelling System - Residential Sector Demand Module (NEMS-RSDM) (Mundaca and Neij, 2009).

Game theory and accounting framework modelling approaches are also considered to be types of simulation models (SENSFuss, 2008), but also limited to the energy conversion sector. Game theory simulation methods concentrate on the interaction of players on energy markets (strategic decisions) and are commonly used in the energy conversion modelling of market design aspects and market power analysis, especially with respect to stable equilibria analysis (Nashequilibrium). In addition, models such as Cournot, Bertrand and Supply Function Equilibria are simulation approaches employed to research oligopolistic electricity markets. A recent model application for electricity sector analysis is the hybrid Bertrand-Cournot model, where Yao and Oren propose a simulation model of a simplified electricity sector with special emphasis on the transmission situation and prices and the analysis of market and power (YAO et al., 2010).

Accounting frameworks can be considered to be a simple form of a simulation model which aims to account for the physical and economic flows of the energy system (Heaps, 2002; Mundaca and Neij, 2009). Instead of explicitly modelling 'players' decisions, this type of model accounts for the outcomes of the assumed development (i.e. of a scenario as a consistent bundle of boundary conditions or of a penetration of a particular new technology) in a descriptive manner (e.g. development of technologies resulting from re-investments of 
new generations of technologies; description of the present routines in decision making in energy technologies) or in a prescriptive manner (e.g. impacts from high-efficient technologies or renewable energies resulting from one or various policy instruments). This approach is commonly applied to project future energy demand of final energy sectors and the related emissions.

Examples of accounting frameworks include models such as Long-Range Energy Alternatives Planning (LEAP); National Impact Analysis (NIA); Bottom-Up Energy Analysis System (BUENAS); Model for Analysis of Energy Demand (MAED); and the Policy Analysis Modelling System (PAMS). Due to their simple structure, accounting frameworks are not commonly applied to simulate decision processes.

\subsubsection{Multi-Agent Models}

Multi-agent modelling is a simulation approach which considers market imperfections such as strategic behaviour, asymmetric information and other non-economic influences. The concept and architecture of multi-agent models is derived from the distributed artificial intelligence concept whose application has been greatly extended across several research areas (e.g. macro level complexities) since the early 1990s. Advances in computational methods and resources and in complex, multi-disciplinary ecological and natural resource research methodologies combined with progress in more specialised statistical approaches have allowed researchers to expand the use of agent-based modelling, especially to decisionand policymakers (Foley et al., 2005; Heemskerk et al., 2003).

Agent-based models are considered to be more than just innovative research tools for analysing complex systems, but are also regarded as an instrument for end-users to improve decision-making as well as to test specific policies and project alternative scenarios and futures (AleXandridis and Pijanowski, 2006). An important aspect with respect to micro-level interactions relates to the role of the defined agents as well as to the decisions and interactions between heterogeneous actors in the system. In this respect, agents have in common the ability to act autonomously, interact with other agents, react to the environment, and take the initiative to act (Wooldridge, 1995, 2009).

Agent-based models applied to the electricity sector are widespread in literature. Traditionally, they tended to focus on operational aspects rather than on long-term simulations until recently when some agent models have been applied to long term planning due to the reasoning that the capacities are being built up as the result of investment decisions. Fichtner et al. (2003) suggest the combined application of an agent-based approach and a linear optimisation model for 
strategic planning patterns of electricity suppliers in liberalised markets. Further examples in this field include the research carried out by WiTtMANN (2008), who developed an agent-based model of energy investment decisions in urban energy systems with the focus on decentralised converting technologies.

In addition, the tool PowerACE was also developed within an agent-based platform in order to analyse the German electricity and focused on three main topics. First, Sensfuss (2008) and Sensfuss et al. (2008) analysed the impact of renewable electricity generation on the electricity market. Another part of the model investigates the role of learning algorithms in price building mechanisms on the electricity market and the impact of market structure and design on electricity prices (Weidlich and VeIt, 2008). The third topic looked at long-term developments in terms of investment decisions in the conventional power sector (Genoese et al., 2007) and market power (Möst and Genoese, 2009).

So far, the multi-agent models are limited to applications of the energy converting technologies and a few applications on final energy sectors (e.g. Jochem, 2009). One major obstacle of developing and using multi-agent models is the enormous demand on additional empirical data in order to simulate the behaviour of the different agents.

\section{Top-Down versus Bottom-Up}

Between the late 1970s and the 1990s many debates about the quality of energy demand projections and the related impacts on the economy and society could be witnessed at international conferences, energy symposia, or seminars (KRAUSE, 1996; Manne and Richels, 1990). There was insufficient understanding of the strengths, weaknesses, and limitations of the top-down and bottom-up models used by the different disciplinary communities, but with the increasing interdisciplinary competence of energy research teams over the last decade there has also been a growing demand to combine the two approaches and, hence, their advantages.

\subsection{Strengths, Weaknesses and Limitations}

In relation to the above mentioned models one can generalise certain advantages and disadvantages for top-down and bottom-up modelling.

One major advantage of top-down energy models is their application of feedback loops to welfare, employment, and economic growth. This endogenous assessment of economic and societal effects results in higher consistency and 
facilitates a comprehensive understanding of energy policy impacts on the economy of a country or region. On the other hand, top-down models suffer from the lack of technological detail and deliver rather generalised information. Consequently, they might not be able to give an appropriate indication of technological progress (as they do not directly model technological change - this is only considered via substitution elasticities), non-monetary barriers to energy efficiency or specific policies for certain technologies or branches. Especially in the long run, when substantial technological change, saturation, and intra-sectoral structural change can be expected and has to be included in a plausible model, top-down models are not suited to show in a transparent manner credible technology futures.

Furthermore, driven by the assumption of efficiently allocating markets, topdown modelling approaches tend to underestimate the complexity of obstacles and their non-monetary form like lack of knowledge, inadequate decision routines, or group-specific interests of technology producers or of whole sales. CGE models assume that any policy implies additional cost, although highly profitable (but unrealised) investments in energy efficiency may reduce cost and increase profits and tax income. Transaction costs are only implicitly covered and cannot be changed by relevant policies such as technical standards or energy efficiency networks. Finally, as they are focused on monetary terms, they consequently tend to favour monetary related policies, e.g. price-based (taxes, subsidies, etc.) policies or emission certificates and regulatory (bans and rules) policies (HourCADE et al., 2006).

In contrast to macroeconomic modelling, bottom-up modelling approaches incorporate a high degree of technological detail which enables them to present very detailed pictures of energy demand and energy supply technologies, as well as plausible technology futures. Bottom-up models can also give detailed evaluations of sector- or technology-specific policies (CatenazzI, 2009). However, this high degree of detail means that bottom-up modellers are heavily dependent on data availability and credibility with regard to their many assumptions on technology diffusion, investments and operating cost. There are also criticisms of bottom-up modelling concerning the neglect of programme costs, the feedback of energy policies as well as the lack of macro-effects of the presumed technological change on overall economic activity, structural changes, employment, and prices. 


\subsection{Hybrid Energy System Models}

To overcome the above mentioned weaknesses and limitations of conventional top-down and bottom-up energy models, energy modelling is currently moving in the direction of hybrid energy system modelling combining at least one macroeconomic model with at least one set of bottom-up models for each final energy sector and the conversion sector. According to Hourcade et al. (2006) and Bataille (2005) a high-quality hybrid model system should incorporate at least three properties: (1) technological explicitness, (2) microeconomic realism and (3) macroeconomic completeness. Top-down modelling on its own provides energy modellers with a high degree of macroeconomic completeness through the feedback loops for economy, welfare, etc. combined with microeconomic realism, e.g. the decision-making processes of the different agents, etc. (see Section 2.1). Pure bottomup modelling, on the other hand, offers a high level of technological explicitness and a low level of macroeconomic completeness (see Section 2.2). Merging these three properties into one hybrid system can take place in several different ways. The simplest form of linking top-down and bottom-up approaches, also called 'soft linking', is the manual transfer of data, parameters and coefficients. If this transfer is further evolved using automatic routines, a 'hard link' is established between the different models. This form of a 'soft link' has been applied in Swiss energy demand and supply projections in a rather complex model setting of a macroeconomic model and several bottom-up models for all final energy sectors and the conversion sector by four model teams (BFE, 2007).

The rather simple hybrid bottom-up CGE model SCREEN (Sustainability Criteria for Regional Energy policies) for Switzerland, has also been developed, combining technological details of the electricity sector with a macroeconomic CGE framework (Kumbaroglu and Madlener, 2001). It was used to analyse the effects of a $\mathrm{CO}_{2}$ tax in Switzerland, but was not further developed.

The next step for connecting top-down and bottom-up models is to apply partial model elements (top-down or bottom-up) in their modelling counterparts. Catenazzi (2009) defines two hybrid energy model systems in this context: 'macroeconomic models with bottom-up energy supply models' and 'bottom-up models with some limited macroeconomic sub-models'. The MARKAL model family is an example for the latter (see Section 2.2.2). A similar approach is used by Hourcade et al (2006), who define the following three categories of hybrid energy models: 'bottom-up models with macroeconomic feedbacks', 'bottom-up models with microeconomic behavioural parameters for technology choices' and 'top-down models with more technological explicitness or parameters for endogenous technological change’. 
One of the presently established hybrid model systems was applied in the ADAM project (Adaptation and Mitigation Strategies), a European energy model (Jochem et al., 2007). The model system in ADAM combines a macroeconomic model (E3ME), with a set of bottom-up models for the four final energy sectors (industry, services, transport and the residential sector which has been split up into buildings and electrical appliances). This hybrid system has been applied to project the energy demand and supply of 29 European countries up to 2050 in various scenarios (Jochem et al., 2007; ScHADE et al. 2009).

Challenges facing hybrid energy modelling include, amongst others, the need to keep such combined model systems theoretically consistent and empirically valid without constructing huge models that are incomputable. Additionally, the endogenous consideration of structural change (inter-sectoral as well as intrasectoral) and technological progress are important issues that require further attention and research.

\subsection{Linking the Results of Process-Based Models and Macroeconomic Models}

Presently, there are scarcely any hard links between process-oriented energy models and macroeconomic models. This is due to the disciplinary cultures in which each type of energy model has been developed. Linking the models is mostly limited to a manual transfer of a few major drivers (e.g. population, gross value added of the economic sectors, or energy prices on world markets) and to investment figures (often only from the energy conversion sector of bottom-up models being transferred to macroeconomic models). On top of this, the few existing links have not been implemented in electronically based transformation modules ('hard links'), but are manually transferred by the researchers and teams involved (e.g. the Energy Perspectives of Switzerland; see BFE, 2007).

The need to link these two 'worlds' is the challenge presently facing energy demand and supply modelling. Analysts have to simulate the projected futures in both types of models in a consistent way which may induce the need for one or two iterative runs between the two types of models simulating those policy scenarios that deviate substantially from a reference scenario (e.g. a climate change scenario with substantial reductions of greenhouse gas emissions during the next few decades, assuming substantial increases in energy and material efficiency and intensive use of renewable energies). For example, the TRANSFORM module of the ADAM project translates monetary production data of basic goods industries into physical production. It also incorporates improvements in material efficiency and material substitution and saturation by the MATEFF model; a bottom-up model for simulating those effects on basic products like steel, cement, 
non-ferrous metals, paper, glass, etc. Finally, the IMPULSE module of this hybrid model system collects all data of the bottom-up models on investments, changing operating cost (including energy cost), and the programme costs, stemming from the policies assumed in a particular scenario. (Jochem et al., 2007; SCHADE et al. 2009). To relate the specific energy demand of basic materials to their physical production and not to monetary production data is very important in order to arrive at realistic and transparent results in energy demand projections of basic product industries.

Additional policy efforts in energy and material efficiency as well as in renewable energies imply a substitution of energy uses by increasing capital investments and related employment. These policies generally induce programme costs for governments and industrial associations which can be relevant in real terms - or at least in the political debate. Hybrid models can analyse essential questions for detailed climate change policies reflected in bottom-up models on the one hand and the impacts of those mitigation scenarios on the economy by macroeconomic models on the other hand.

\section{Conclusions}

Hybrid energy system models help understand the advantages and limitations of the existing bottom-up and top-down energy models and to improve the consultation process of the energy analysts for decision-makers in governments, international institutions (e.g. IEA, UNEP) and large energy supply companies as well as energy technology producers. While the energy models on both levels (bottom-up and top-down) are further improved by more detailed structures, more empirically based equations and adding multi-agent aspects, the progress of the development of hard links of the two modelling levels is of crucial interest. In the near future, transformation modules should intensify the interaction between process-oriented models and macroeconomic models by implementing computer-based hard links; example are: (1) the development of living areas of the residential sector derived from relationships of demographic variables, income per capita, and other preferences of private households; (2) the mileage of cars, trucks, ship, or public transport depending on demographic variables, per capita income, foreign trade and industrial production, and inter-industrial structural change. In addition, the different impacts on material substitution or material efficiency in energy-intensive industries should be modelled in more detail based on numeric factors and relationships. In this context, export/import ratios and detailed recycling data of the different basic products should be taken into account. 
In the more distant future, company size (e.g. small, medium, big) and the influences of barriers and supporting factors of energy efficiency measurements should also be implemented in bottom-up models in order to improve the transparency between potentials, obstacles, and impacts of sector- or technology-oriented policies. The progress expected will lead to a more transparent simulation of sector- and technology-oriented policies by governments and trade associations and to more reliable information of the impacts of those policies at the economic and societal level.

\section{References}

Alexandridis, K. T., and B. C. Pijanowski (2006), "Modular Bayesian Inference and Learning of Decision Networks as Stand-Alone Mechanisms of the MABEL Model: Implications for Visualization, Comprehension, and Policy-Making", Argonne National Laboratory and the University of Chicago.

Bahn, O., and C. Frei (2000), "GEM-E3 Switzerland: A Computable General Equilibrium Model applied for Switzerland”, Paul Scherrer Institut (PSI), General Energy Research Department (ENE), Villigen.

Bataille, C. G. F. (2005), "Design and Application of a Technologically Explicit Hybrid Energy-Economy Policy Model with Micro and Macro Economic Dynamics", Thesis in the School of Resource and Environmental Management, Simon Fraser University.

Bernard, A., and M. Vielle (2008), "GEMINI-E3, A General Equilibrium Model of International-National Interactions between Economy, Energy and Environment", Computational Management Science, 5(3), pp. 173-206.

BFE (Bundesamt für Energie) (2007), Die Energieperspektiven 2035 - Band 1 Synthese, Bern.

BöHringer, C. (1998), "The Synthesis of Bottom-Up and Top-Down in Energy Policy Modelling”, Energy Economics, 20, pp. 233-248.

Böhringer, C., and A. Löschel (2006), "Promoting Renewable Energy in Europe: A Hybrid Computable General Equilibrium Approach", Special Issue of the Energy Journal, Hybrid modeling of energy-environment policies: Reconciling bottom-up and top-down.

Böhringer, C., and T. Rutherford (2006), "Combining Top-Down and Bottom-Up Analysis in Energy Policy Analysis", Technical Report Discussion paper 06-07, ZEW.

Böhringer, C., and T. Rutherford (2008), "Combining Bottom-Up and TopDown”, Energy Economics, 30, pp. 574-596. 
CAMECON (2011), Cambridge Econometrics, website: http://www.camecon. co.uk/ModellingTraining/suite_economic_models/E3ME.aspx.

Capros, P., et al. (1996a), "Double Dividend Analysis: First Results of a General Equilibrium Model (GEM-E3) Linking the EU-12 Countries", in Environmental Fiscal Reform and Unemployment, C. Carraro and D. Siniscalco, eds., Kluwer Academic Publishers.

Capros, P., and P. Georgakopoulos (1996b), "Coordinated versus Uncoordinated European Carbon Tax Solutions Analysed with GEM-E3 Linking the EU-12 Countries", in Economic Aspects of Environmental Policy, S. Proost, eds., Kluwer Academic Publishers.

Catenazzi, G. (2009), "Advances in Techno-Economic Energy Modeling: Costs, Dynamics and Hybrid Aspects", Dissertation, Swiss Federal Institute of Technology (ETH), Zürich.

CES (2008), “The GEM-E3 Model. A General Equilibrium Model for Europe and the World", Centre for Economic Studies, KULeuven, Belgium.

De Vries, B., M. Janssen, A. Beusen, et al. (1999), "Perspectives on Global Energy Futures: Simulations with the TIME Model”, Energy Policy, 27, pp,477-494.

E3Mlab (2007), "The Primes Model: Version Used for the 2007 Scenarios for the European Commission including new Sub-Models Recently Added", website: http://www.e3mlab.ntua.gr/DEFAULT.HTM.

Enerdata (2011), Enerdata global energy intelligence, website: http://www. enerdata.net/enerdatauk/solutions/energy-models/poles-model.php.

ETSAP (2001), ETSAP, website: http://www.etsap.org/markal/main.html.

ETSAP (2005), "Documentation for the TIMES Model: Part 1", April 2005, website: http://www.etsap.org/tools.html.

Eurostat (2008), "Eurostat Manual of Supply, Use and Input-Output Tables", Methodologies and Workingpapers, 2008 edition, Luxembourg.

EWI (2011), Energiewirtschaftliches Institut an der Universität zu Köln, website: http://www.ewi.uni-koeln.de/Elektrizitaetsmodell.154.0.html.

Fichtner, W., D. Möst, M. Wietschel, C. Weinhardt, and O. Rentz (2003), „Zur strategischen Planung bei Energieversorgern in liberalisierten Energiemärkten“, WiSt- Wirtschaftswissenschaftliches Studium, 32 (12), pp. 707-713.

FSO (2010), Federal Statistical Office, website: http://www.bfs.admin.ch/bfs/ portal/en/index.html.

Foley, J., et al. (2005), "Global Consequences of Land Use", Science, 309, 570, DOI: 10.1126/science.1111772. 
Forrester, J. W. (1958), "Industrial Dynamics - A Major Breakthrough for Decision Makers", Harvard Business Review, 36(4), pp.37-66.

Forrester, J. W. (1962), Industrial Dynamics, 2nd edition, MIT Press, John Wiley \& Sons, New York.

Forrester, J. W. (1971), World Dynamics, Wright-Allen Press, Cambridge MA. Forrester, J. W. (1980), "System Dynamics - Future Opportunities", in System Dynamics. TIMS Series in the Management Sciences, Augusto A. Legasto, Jay W. Forrester, and James M. Lyneis, eds., vol. 14, pp.7-21, Amsterdam: North-Holland.

Genoese, M., F. Sensfuss, and D. Moest (2007), "Power Plant Investments under Different Emission Allocation Schemes", Proceedings of the 9th IAEE European Conference on Energy Economics (10-12 June 2007), Florence, Italy.

Greene, W. H. (2003), Econometric Analysis, Fifth Edition, New York University, Pearson Education, New Jersey.

Heaps, C. (2002), "Global Scenario Group Futures", SEI, technical notes, report 9.

Heemskerk, M., K. Wilson, and M. Pavao-Zuckerman (2003), "Conceptual models as tools for communication across disciplines", Conservation Ecology, 7(3): 8.

Hourcade, J. C., et al. (2006), "Hybrid Modeling: New Answers to Old Challenges", The Energy Journal 2, Special issue (2006) pp. 1-12, C.I.R.E.D., Nogent-sur-Marne cedex.

IEA (2010), "World Energy Outlook 2010", International Energy Agency, Paris Cedex, France.

IEA (2011), "World Energy Model - Methodology And Assumptions", International Energy Agency, Paris Cedex, France.

Jochem, E., T. Barker, S. Scrieciu, W. Schade, N. Helfrich, O. Edenhofer, N. Bauer, S. Marchand, J. Neuhaus, S. Mima, P. Criqui, J. Morel, B. Chateau, A. Kitous, G. J. Nabuurs,, M. J. Schelhaas, T. Groen, L. Riffeser, F. Reitze, E. Jochem, G. Catenazzi, M. Jakob, B. Aebischer, K. Kartsoni, W. Eichhammer, A. Held, M. Ragwitz, U.Reiter, S. Kypreos, and H. Turton (2007), "EU-Project ADAM: Adaption and Mitigation Strategies: Supporting European Climate Policy - Deliverable M1.1: Report of the Base Case Scenario for Europe and Full Description of the Model System", Fraunhofer ISI, Karlsruhe, November 2007.

Jochem, E., T. Barker, S. Scrieciu, W. Schade, N. Helfrich, O. Edenhofer, N. Bauer, S. Marchand, J. Neuhaus, S. Mima, P. Criqui, J. Morel, B. Chateau, A. Kitous, G. J. Nabuurs,, M. J. Schelhaas, 
T. Groen, L. Riffeser, F. Reitze, E. Jochem, G. Catenazzi, M. Jakob, B. Aebischer, K. Kartsoni, W. Eichhammer, A. Held, M. Ragwitz, U.Reiter, S. Kypreos, and H. Turton (2007) (2008), "EU-Project ADAM: Adaption and Mitigation Strategies: Supporting European Climate Policy Deliverable M1.2: Report of the Reference Case Scenario for Europe”, Fraunhofer ISI, Karlsruhe, November 2008.

Jochem, P. (2009), "A CO2 Emission Trading Scheme for German Road Transport - Assessing the Impacts using a Meso Economic Model with MultiAgent Attributes", Nomos, Baden-Baden

Krail, M., and W. Schade (2010), "The Potential of Alternative Fuel Cars for Achieving CO2 Reduction Targets in EU27”.

krause, F. (1996), "The Costs of Mitigating Carbon Emissions: A Review of Methods and Findings from European Studies", Energy Policy Vol 24, no 10, p. 899-915.

Kumbaroglu, G., and R. Madlener (2001), "A Description of the Hybrid Bottom-Up CGE Model SCREEN with an Application to Swiss Climate Policy Analysis", CEPE Working Paper No. 10, Zürich.

Linares, P., F. J. Santos, M. Ventosa, and L. Lapiedra (2008), "Incorporating Oligopoly, CO2 Emissions Trading and Green Certificates into a Power Generation Expansion Model", Automatica, vol. 44, no. 6, pp. 1608-1620.

Löschel, A. (2002), "Technological Change in Economic Models of Environmental Policy: A Survey”, Ecological Economics, 43, pp. 105-126.

Loulou, R., G. Goldstein, and K. Noble (2004), "Documentation for the MARKAL Family of Models", Energy Technology Systems Analysis Programme (ETSAP), website: www.etsap.org.

Manne, A, and R. G. Richels (1990), " $\mathrm{CO}_{2}$ Emission Limits: An Economic Cost Analysis for the USA", The Energy Journal vol. 11(2), pp. 51-74

Manne, A., and R. G. Richels (2004), "MERGE: A Model for Evaluating the Regional and Global Effects of GHG Reduction Policies", website: www. standford.edu/group/MERGE.

Mayer, H. (2007), "Calculation and Analysis of a Hybrid Energy Input-Output Table for Germany within the Environmental-Economic Accounting (EEA)", Paper presented at the 16th International Input-Output Conference 2-6 July 2007 Istanbul/Turkey, Statistisches Bundesamt, Wiesbaden.

Messner, S., and M. Strubegger (1995), "User's Guide for MESSAGE III", WP-95-69. International Institute for Applied Systems Analysis, Laxenburg, Austria.

Möst, D., and M. Genoese (2009), "Market Power in the German Wholesale Electricity Market", The Journal of Energy Markets, 2 (2), pp. 47-74. 
Mundaca, L., and L. Neij (2009), "A Multi-Criteria Evaluation Framework for 'Tradable White Certificate' Schemes", Energy Policy, 37(11), pp. 4557-4573.

Nathani, C., M. Wickart, R. Oleschak, and R. van Nieuw koop (2006), "Estimation of a Swiss Input-Output Table for 2001", CEPE Report No. 6, Centre for Energy Policy and Economics (CEPE), Zürich.

Nathani, C. (2006), "Material Use and Induced Energy Demand: an InputOutput Analysis,", ETH Zürich, Paper to be presented at the Intermediate International Input-Output Meeting on Sustainability, Trade and Productivity, Japan.

Prognos AG (2011), „Das Energiewirtschaftliche Gesamtkonzept. Konzept eines beschleunigten Ausstiegs aus der Kernenergie in Deutschland“, im Auftrag der Vereinigung der Bayerischen Wirtschaft e. V.

Russ, P., and P. CRiqui (2007), "Post-Kyoto CO2 Emission Reduction: The Soft Landing Scenario Analysed with POLES and Other World Models", IPTS and Grenoble University.

Schade, W. (2004), "Strategic Sustainability Analysis: Concept and Application for the Assessment of European Transport Policy", Dissertation, NOMOSVerlag, Baden-Baden.

Schade, W., and M. Krail (2006), Modeling and Calibration of Large Scale System Dynamics Models: The Case of the ASTRA Model.

Schade, W., E. Jochem, T. Barker, G. Catenazzi, W. Eichhammer, T. Fleiter, A. Held, N. Helfrich, M. Jakob, P. Criqui, S. Mima, L. Quandt, A. Peters, M. Ragwitz, U. Reiter, F. Reitze, M. Schelhaas, S. SCrieciu, and H. Turton (2009), "ADAM - 2 degree scenario for Europe policies and impacts. Deliverable M1.3 of ADAM (Adaptation and Mitigation Strategies: Supporting European Climate Policy)", Project funded by the European Commission 6th RDT Programme. Karlsruhe, Germany.

Seebregts, A. J., G. A. Goldstein, and K. E. Smekens (2002), "Energy/environmental modeling with the MARKAL family of models", in Operations Research Proceedings 2001, Chamoni, R., Leisten, A., Martin, J., Minneman, Stadtler, H., eds., pp. 75-82, Duisburg, Germany.

Sensfuss, F. (2008), "Assessment of the Impact of Renewable Electricity Generation on the German Electricity Sector - An Agent-Based Simulation Approach", Doctoral Thesis, University of Karlsruhe.

Sensfuss, F., M. Ragwitz, and M. Genoese (2008), "The Merit-Order Effect: A Detailed Analysis of the Price Effect of Renewable Electricity Generation on Spot Market Prices in Germany", Energy Policy, 36 (8), pp.3086-3094.

Tinter, G. (1953), "The Definition of Econometrics", Econometrica, 21(1), pp.31-40. 
UNEP (2011), "Recycling Rates of Metals - A Status Report", $2^{\text {nd }}$ Report of the Global Metal Flows working group of the International Panel of Sustainable Resource Management of UNEP.

United Nations (1999), "Handbook of Input-Output Table Compilation and Analysis", Studies in Methods, Series F No. 74, UN, New York.

Ventosa, M., Á. Baíllo, A. Ramos, and M. Rivier (2005), "Electricity Market Modeling Trends", Energy Policy, 33(7), pp. 897-913.

Weidlich, A., and D. Veit (2008), "A Critical Survey of Agent-Based Wholesale Electricity Market Models”, Energy Economics, 30(4), pp. 1728-1759.

Wittmann, T. (2008), "Agent-Based Models of Energy Investment Decisions", Doctoral Thesis, Technical University of Berlin, Physica-Verlag Heidelberg. Wooldridge, M., and N. R. Jennings (1995), "Intelligent Agents: Theory and Practice”, Knowledge Engineering Review, 10 (2), pp. 115-152.

Wooldridge, J. M. (2002), Econometric Analysis of Cross Section and Panel Data, Massachusetts Institute of Technology, The MIT Press, Cambridge, London.

Wooldridge, M. (2009), An Introduction to MultiAgent Systems, John Wiley $\&$ Sons, Chichester.

Worrel, E., S. Ramesohl, and G. Boyd, (2004), "Advances in Energy Forecasting Models Based on Engineering Economics", Annu. Rev. Environ. Resour., 29, 345-81.

WWF (2009), „Modell Deutschland. Klimaschutz bis 2050: Vom Ziel her denken“, WWF Deutschland, Prognos AG, Öko-Institut e.V., Basel/Freiburg/ Berlin.

YaO, J., S. S. Oren, and B. F. Hobbs (2010), "Hybrid Bertrand-Cournot Models of Electricity Markets with Multiple Strategic Subnetworks and Common Knowledge Constraints", in Restructured Electric Power Systems, X.-P. Zhang, eds., John Wiley \& Sons, Inc., Hoboken, NJ, USA.

\section{SUMMARY}

The energy demand and supply projections of the Swiss government funded by the Swiss Federal Office of Energy and carried out by a consortium of institutes and consulting companies are based on two types of energy models: macroeconomic general equilibrium models and bottom-up models for each sector. While the macroeconomic models are used to deliver the economic, demographic and policy framework conditions as well as the macroeconomic impacts of particular scenarios, the bottom-up models simulate the technical developments in the final energy sectors and try to optimise electricity generation under the given boundary 
conditions of a particular scenario. This introductory article gives an overview of some of the energy models used in Switzerland and - more importantly - some insights into current advanced energy system modelling practice pointing to the characteristics of the two modelling types and their advantages and limitations. 